\title{
Missionary Zeal: some problems with the rhetoric, vision and approach of the AHELO programme
}

\section{Introduction}

As global participation in higher education has risen, there have been an increased focused on the quality of students' experiences of higher education. Defining quality is a difficult conceptual problem. Should it defined by the prestige of the institution in which students study; by what students say about their experiences; by what students can do once they graduate or by the ways students are transformed by their university experiences? Further complicating this situation are the different roles that notions of quality need to play. Measures of quality need to be portable and durable across contexts and time so that they can be used to make meaningful comparisons. However, they also need to tell us something valid about how students change through their engagement in particular courses, which is an individual and unpredictable process. It is dependent on the relations between the course and the student: students need to take full advantage of the opportunities that are offered and this is not something that can be guaranteed at the outset.

The OECD's AHELO (Assess ment of Higher Education Learning Outcomes) project is one approach to dealing with these issues of defining and measuring the quality of global higher education. It seeks to compare the quality of what students' learn in different institutions and countries (see Ewell 2012 for an outline of its development). It is made up of four elements: a disciplinary element which is focused on measuring students' learning outcomes in economics and engineering; a generic skills element that is aimed at all 
disciplines; the collecting of contextual information; and an element focused on the estimation of value-added (see Tremblay et al. 2012; OECD 2013a, 2013b).

In this piece I examine three issues with AHELO: the way that the case for the need for AHELO is made, the vision of higher education that is offered by AHELO, and AHELO's focus on measuring generic skills. Based on these, I argue that even if AHELO succeeded in its own terms, it would not meet its stated aims. I conclude by arguing that the seductive vision it offers of a simple and robust measure of the comparative quality of learning outcomes globally is a mirage. Instead we should focus on the more quotidian task of engaging stakeholders internationally in discussions about the development of high quality undergraduate higher education.

\section{A genuine problem presented in a problematic manner}

From the outset I want to be clear that AHELO is attempting to respond to a genuine problem in the measurement of higher education quality. There are strong pressures for the measurement of how students benefit from higher education to ensure equitable higher education for all students regardless of which institution they study in. The legitimacy of these demands needs to be recognised as governments, students and societies invest considerable resources in higher education.

Positions in national and international higher education league tables have become a dominant way of representing the quality of the education on offer to students. Their attraction is understandable: they travel across a number of contexts and audiences, have resonance for prospective students and their families, employers, policy makers, academics 
and universities, and international bodies (Hazelkorn 2015). However, their shortcomings are well rehearsed: they tend to involve unrelated and incomparable measures that are brought together into a single score by algorithms and weightings that lack any statistical credibility. Crucially, the stability at the top of the league tables reinforces privilege: higher status institutions tend to take in a much greater proportion of privileged students. League tables strongly and wrongly suggest that students who have been to these institutions have received a higher quality education (Ashwin et al. 2012). Thus league tables distort our understanding of quality by making it about history and prestige rather than about the ways in which students are given access to powerful knowledge.

In attempting to provide a measure of quality that does not reinforce historical institutional status, the OECD is attempting to do something important and valuable. However, the OECD offers a very particular version of this problem in building its case for AHELO. Essentially, rather than being presented as a question of what is valued and valuable, it is presented simply as a question of efficient and effective measurement that AHELO is best placed to answer. However, there are clear asymmetries in the way this case is presented which undermine the claim that AHELO is subjected to an impartial evaluation. There are three elements of this asymmetry: asymmetries in the ways that AHELO and its alternatives are handled; asymmetries in the ways in which academics who are supportive and critical of AHELO are presented; and asymmetries in the way in which AHELO is presented when it is being advocated and when it is being defended from criticism. In order to show that these asymmetries exist in the same documents, I will focus on the first volume of feasibility study which outlines the design and implementation of AHELO (Tremblay et al. 2012), although similar tensions exist in the other two volumes (OECD 2013a,b). 
In arguing for AHELO as the best form of measurement, there is notable asymmetry in the way that AHELO and alternatives to AHELO are dealt with. As Morgan and Shahjahan (2014) argue, AHELO is presented as a scientific, objective and reliable whereas alternatives are presented as biased. In the discussion of alternatives to AHELO, measures of student satisfaction are rejected because they are not measures of learning and are not culturally sensitive; students' self reports of their learning gain are rejected because they do not correlate with outcomes; graduate surveys are rejected because of differences in the economic conditions in different countries; and actual degree results are rejected as too locally focused. All of these measures are dismissively labelled 'proxies' and contrasted with the state of the art, direct measure of learning outcomes provided by AHELO. However, none of these potential shortcomings are explored in relation to AHELO even though they could equally apply to any measure, including AHELO. For example, there is nothing direct about using students' performance on generic skills tests to measure their learning in their degree courses. Thus this first aspect of asymmetry is that demands are made of existing measure of outcomes that are not made of AHELO.

A second element of this asymmetry is the way that the views of academics are handled within AHELO documentation. Those who are engaged in the AHELO project are presented as 'the experts' (for example, this phrase is used 41 times in Tremblay at al. 2012). Their views are portrayed in terms of consensus and they are usually referred to as a collective body that 'acknowledged', 'agreed', 'recommended', 'recognised', and 'suggested' things. There is no sense of who precisely is being referred to in each case and whether there were any disagreements between them. The sense conveyed is that these are unanimously held 
views of 'the experts' and, as such, are not open to question. Academics who question aspects of the AHELO process are dealt with in very different terms. For example, the response to concerns raised about the generic skills tests are dismissed as 'anxieties' and the response seems, strangely, to suggest that the instruments used to prove the concept of AHELO will not shape what AHELO looks like in the future:

"Notwithstanding the fact that all instruments chosen for the feasibility study were only intended to prove a concept and do not pre-judge what an eventual future AHELO might look like, they have certainly fuelled anxieties in some academic circles." (Tremblay at al. 2012, p.69).

Related to this quotation, a third problematic element of the case that is made is that the significance and scope of the AHELO project changes according to whether the project is being advocated or protected from criticism. In advocate mode, Tremblay et al. (2012, p.35) write:

"Given its international scope, the AHELO concept reflects the most advanced manifestation of a generalisable test that could potentially provide independent insights into learners' knowledge, capacity, and their ability to apply knowledge and skill to solve real-world problems."

Yet later, in the same document, criticisms are dismissed for overestimating the intended scope of AHELO and are positioned as 'fears' rather than genuine concerns. For example: "The criticisms forwarded above are somewhat exaggerated, to the extent that as AHELO has never been intended to replace other forms of classroom and institutional assessments or student surveys, nor has it meant to provide the sole yardstick by which to judge higher 
education quality. Nevertheless, it is important to take notice and have a good understanding of the underlying fears behind some common arguments against AHELO". (Tremblay et al. 2012, p.61)

Whilst this response to the criticisms does not directly contradict the earlier excerpt, the point being made is that the critics are overestimating the potential scale and impact of the AHELO project. This is a sentiment that does contradict the presentation of AHELO in the earlier excerpt.

These three elements of the rhetorical approach give the feasibility study the feeling of a testament of faith in the AHELO concept rather than a rigorous review of whether it is feasible. This is echoed by Altbach's (2015) observation that, despite recommendations by various bodies (including by the OECD's own committee) to end it, the AHELO project has continued to roll on.

\section{AHELO's vision of higher education}

A second problem with the AHELO approach is the vision of higher education that is created by the way in which it measures learning outcomes. For example Shahjahan et al. (2015), through a review of AHELO texts, show how AHELO create particular images of students and learning. They argue that students are constructed as passively acquirers of pre-defined content and as buyers of educational goods.

The generic skills element of AHELO also presents a problematic vision of the purposes of higher education. Given that this is the aspect of AHELO that potentially involves the most 
students and courses, it is a serious problem. The generic tests used by AHELO are adapted versions of the US Collegiate Learning Assessment (CLA) in which students are asked to answer a series of questions which require them to interpret and draw conclusions from a variety of sources of information. Students' responses are assessed in terms of the extent to which they demonstrate skills such as 'analytical reasoning and evaluation', 'problem solving', and 'writing effectiveness'. The illustrative examples provided in the feasibility study include tasks in which students are asked to provide responses to a mayor about a deformed catfish that has been found in a local lake (see Tremblay et al. 2012).

In assessing the learning outcomes of higher education through an assessment of students' generic skills, AHELO positions higher education as about the development of generic skills. These generic skills are argued to be outcomes that are not specific to any particular subject but would be desired by students in any discipline (Tremblay et al 2012). Whilst it is argued that there is "wide acceptance in the academic global community that the development of generic skills and competencies should be an integral part of academic studies" (Tremblay et al 2012, p.63), this does not mean that the development of such generic skills should be the primary measure by which students' learning outcomes are judged. An alternative position is that what makes an undergraduate education a higher education is the personal relationships that students develop with particular bodies of knowledge (Ashwin 2014) and that it is these relationships to knowledge which provide the transformative aspects of higher education that is so highly valued by students, governments and societies (for example see Ashwin et al. 2014). The key point here is that the claim that a key measure of higher education is the generic skills that students develop is highly contentious. Having this as the basis of a global comparison of the quality of learning outcomes does far more than 
simply measure the outcomes of higher education. Given that what we choose to measure sends a clear signal about what is valued, it rather positions generic skills as the key learning outcome of higher education.

\section{Further issues with generic skills}

Beyond the vision of higher education that is created, there are two further issues with the use of generic skills tests to measure what students have gained from their study at university. First, there is no clear conceptual link between students' ability to solve a particular set of problems unrelated to their degree programmes and their general ability to solve problems. This approach to generic skills is based on the mistaken notion that people either have good or bad 'reasoning' or 'problem-solving' skills regardless of the particular task they are engaged in or the context in which they are undertaking this task. In contrast, how students engage in a particular task is largely shaped by what is at stake for them in any particular performance and their interactions with other people and things within it (Ashwin 2009). This is because as, Ewell (2012) argues, thinking always has an object and that object plays a crucial role in shaping thought processes, as does the cultural context in which thinking takes place (see Ewell 2012; Shahjahan 2013; Altbach 2015). Thus providing guidance to a mayor will be affected by the cultures in which students are operating and so is not a generic task at all. Assuming such tasks are generic, when students' engagement with them will be based on particular cultural norms, runs the risk of some norms being positioned as more valuable than others (Shahjahan 2013).

Second, as Altbach (2015) argues, there are different levels of familiarity with these kinds of generic tests across global higher education. One would expect students who have more 
experience of undertaking such tests and curricula that are more focused on developing generic skills, such as in the US, to perform better on such tests.

These two issues raise serious concerns about the generic skills tests potential to provide valid comparisons of the quality of students learning outcomes globally. This is because they are likely to tell us as more about the cultural contexts in which students are operating and their level of experiences of undertaking such generic skills tests than they are about what students have gained from studying in higher education.

\section{What if AHELO succeeded?}

Let us assume for a moment that the problems discussed in relation to AHELO's vision of higher education and focus on generic skills are mistaken. We can then examine how things might look if AHELO succeeded in its own terms. So what would be likely to happen if AHELO became a globally significant and respected measure of the quality of students' learning outcomes? As Hazelkorn (2015) argues, measures which set out to support student choice tend to end up being tools by which institutions position themselves globally. Thus if AHELO were successful, then universities would clearly need to take their students' performance in the generic skills tests very seriously. The predictable outcome is that they would invest time and resources in preparing their students to undertake these tests.

Would this tell us anything about the quality of students' engagement with disciplinary and professional knowledge or their ability to perform in the workplace? No, it would primarily tell us about how much time they had spent preparing to take these kinds of generic tests. In this way AHELO suffers from the same problems of the other 'proxies' that it seeks to 
replace. Would it help to improve the quality of higher education? No, it would simply make students better versed in completing generic comprehension exercises. Would it, as has been claimed (see Morgan 2015), reduce the impact of historical institutional hierarchies? This seems unlikely because the wealthier an institution, the more resources it would have available to prepare its students for taking the assessments.

Thus if AHELO succeeded, then the likelihood is that over time it would serve to re-inforce existing hierarchies rather than challenge them. In this way it is difficult to see how AHELO could meet its stated aims even if it succeeded in becoming established as the global measure of student learning outcomes.

\section{Conclusion}

All measures of the quality of students' learning outcomes will simplify and give us a partial picture of what is going on. What is crucial is to seek to be clear what elements are being used to create this picture and to question what they actually say about the higher educational experience of students. A central element of thinking about quality is the extent to which particular degree programmes give students access to knowledge that changes their understanding of the world and themselves. AHELO's focus on generic skills means that it cannot tell us about these kinds of relationships. Equally, institutional responses to a successful version of AHELO are likely to mean that it also cannot challenge established higher education hierarchies. Thus my conclusion is that AHELO in its current form cannot provide a meaningful comparison of students' learning outcomes. 
Given this, how might alternatives approaches be developed for comparing the quality of undergraduate education globally? In developing such approaches, it is important to be clear of a three things that get obscured in the AHELO approach and documentation. First, we have a very good understanding of the factors that lead to high quality learning in higher education. For example, these are clearly expressed in the 10 principles of teaching and learning that came out of the UK Teaching and Learning Research Programme (see Ashwin et al. 2015 for a working through of these principles in relation to higher education). What we already know about high quality teaching, learning and assessment in higher education should be the basis of how we seek to compare the quality of undergraduate education. Second, we need to be clear about the limits of what an undergraduate education is intended to offer. Despite the rhetoric from some policy makers including the OECD, degree results or any form of assessment can never tell us what kind of employee or citizen an individual will become. At best they can tell us about students' engagement with a particular bodies of disciplinary and professional knowledge. This means that we need to avoid grandiose claims about what a robust measure of the quality of higher education can provide to students, employers and policy makers. Third, measuring the learning outcomes of higher education cannot be meaningfully separated from debates about the purposes of higher education. This is because how 'quality' is measured will end up playing a central role in defining what counts as a high quality undergraduate experience.

These three issues mean there can be no silver bullet that tells us unproblematically about what students have gained from higher education. Rather success is likely to be found in far more mundane and everyday approaches involving sustained international partnerships between policy makers, universities, academics and students. 


\section{References}

Altbach, P. (2015). AHELO: the myth of measurement and comparability. University World News. Issue 367, 15 May 2015 (Downloaded on $19^{\text {th }}$ August from http://www.universityworldnews.com/article.php?story=20150515064746124).

Ashwin, P. (2009) Analysing Teaching-Learning Interactions in HigherEducation: Accounting for Structure and Agency London: Continuum.

Ashwin, P. (2014) Knowledge, curriculum and student understanding. Higher Education 67 : 123-126.

Ashwin, P., McLean, M., and Abbas, A. (2012) Quality and Inequality in Undergraduate Courses: A guide for national and institutional policy makers. Nottingham: University of Nottingham.

Ashwin, P., Abbas, A., \& McLean, M. (2014). How do students' accounts of sociology change over the course of their undergraduate degrees? Higher Education, 67: 219-234.

Ashwin, P., Boud, D., Coate, K., Hallett, F., Keane, E., Krause, K-L., Leibowitz, B., MacLaren, I., McArthur, J, McCune, V. \& Tooher, M. (2015) Reflective teaching in higher education. London: Bloomsbury Academic.

Ewell, P. (2012). A world of assessment: OECD's AHELO initiative. Change: The Magazine of Higher Learning, 44(5), 35-42.

Hazelkorn, E. (2014). Reflections on a Decade of Global Rankings: what we've learned and outstanding issues. European Journal of Education, 49: 12-28. 
Morgan, C., and Shahjahan, R. (2014). The legitimation of OECD's global educational governance: Examining PISA and AHELO test production. Comparative Education, 50, 192-205.

Morgan, J. (2015), OECD's AHELO project could transform university hierarchy. Times Higher Education, $7^{\text {th }}$ May 2015. (Downloaded on 19th August from https://www.timeshighereducation.co.uk/news/oecds-ahelo-project-couldtransform-university-hierarchy/2020087.article).

OECD (2013a) Assessment of Higher Education Learning Outcomes Feasibility Study Report: Volume 2-Data Analysis and National Experiences. Paris: OECD.

OECD (2013b) Assessment of Higher Education Learning Outcomes Feasibility Study Report: Volume 3 - Further Insights. Paris: OECD.

Shahjahan, R. (2013). Coloniality and a global testing regime in higher education: Unpacking the OECD's AHELO initiative. Journal of Education Policy, 28: 676-694.

Shahjahan, R. A., Morgan, C., and Nguyen, D. J. (2015). 'Will I learn what I want to learn?'Usable representations,'students' and OECD assessment production. Discourse: Studies in the Cultural Politics of Education, 36: 700-711.

Tremblay, K., Lalancette, D., and Roseveare, D. (2012) Assessment of Higher Education Learning Outcomes Feasibility Study Report: Volume 1 - Design and Implementation. Paris: OECD. 